therapeutic interventions of psychopathic disorder is at best deficient. I see this indicating that the medicalisation of psychopathic disorder is a regrettable, albeit not irreversible, mistake. Moreover, the inclusion of psychopathic disorder in new legislation and practice guideline may cause a further diversion of resources allocated to the severely mentally ill. The guidelines on risk assessment might unwittingly help many psychopathic disorder persons further misuse psychiatric services and elude the penal system. It is unfortunate that the increasing pressure on the psychiatric field to exert a tighter social control on the mentally ill is being dangerously extended by incorporating those who must not be included.

Interestingly, Coid, a member of the report's working party, observes that ". . . the remit has been widened in the government's guidelines to include diagnostic categories where there is no convincing evidence one way or the other that psychiatric treatment is effective ..." (Coid, 1996). Yet, some of the listed factors closely resemble features associated with, and criteria used in the diagnosis of, psychopathic disorder.

I hope that future College guidelines on risk assessment have at least explicit indications of the validation of factors included in the assessment of risk, and clearly defined target cases.

CoID, J. W. (1996) Dangerous patients with mental illness: increased risks warrant new policies, adequate resources, and appropriate legislation. British Medical Journal, 312. 965-966.

Royal College of PSYCHIATRISTS SPECIAL WORKING PARTY ON Clinical ASSESSMENT AND MANAGEMENT OF RISK (1996) Assessment and Clinical Management of Risk of Harm to Other People, Council Report CR53. London: Roya College of Psychiatrists.

DAVID MARCHEVSKY, St Michael's Hospital, St Michael's Road, Warwick, Warwickshire CV34 $5 Q W$

\section{Psychiatry and the death penalty}

Sir: Rob Ferris (Psychiatric Bulletin, December 1997, 21, 746-748) and Peter Hodgkinson (Psychiatric Bulletin, December 1997, 21, 749-750) have performed an important service by bringing attention to the controversial issues raised regarding the role of psychiatry and the death penalty. The points addressed in these two articles extend far beyond the parochial concerns of those of us in the 95 countries, including the United States, that maintain the death penalty. We in the US, benighted in regard to the death penalty, are involved in intense arguments in regard to psychiatrists' participation in executions that have worldwide implications for morality and ethics in medicine.
A number of leading forensic psychiatrists in the US have proposed new principles to make it ethically permissible for psychiatrists to be involved in legal executions. The key rationale, among others, is the concept of 'forensic psychiatry exceptionalism'. This notion asserts that a forensic psychiatrist is not a psychiatrist when performing evaluations for a court and thus is not bound by the traditional ethical principles of most psychiatric societies. As stated by a leading forensic psychiatrist, ". . . forensic psychiatrists. however, work in a different ethical framework, one built around the legitimate needs of the justice system". (Appelbaum, 1996). It is not surprising that forensic psychiatrists have been referred to as 'advocates of justice', as an assistant 'in the administration of justice' or as an 'agent of the state'. This proposal, which should cause dismay to physicians and psychiatrists internationally, makes permissible participation in executions and torture, since the physician may simply state, "I am not bound by traditional medical ethics since I am not acting as a physician". In Illinois in the US, the state legislature has passed a rule that permits physicians to take part in executions, including injection of lethal substances, without losing their licences since in that role they are not acting as physicians!

As the two authors point out, this controversy is still unresolved in the American Psychiatric Association (APA). The American Medical Association (AMA) had passed a resolution in June 1995 that paved the way for more involvement of physicians in executions (Council on Ethical and Judicial Affairs, 1995), but the AMA resolution was not approved by the APA Board of Trustees at its meeting in July 1995. Rather, the resolution was referred to various components of the APA for further discussion and recommendations. Recommendations including setting up a commission and holding a debate. The latter was held at the annual meeting of the APA in May 1997 in San Diego. Noteworthy is that in response to a request to modify the 1995 AMA resolution made at the June 1997 annual AMA meeting, the Council on Ethical and Judicial Affairs of the AMA was asked by the AMA House of Delegates to reconsider its position in regard to physician participation in executions. Thus, this issue is in active discussion in both the APA and the AMA, without resolution at the present moment.

The issue of treatment of a psychotic individual on death row is taken up in the 1995 AMA resolution, but in the words of Dr Hodgkinson. that statement is "too loose and equivocal, requiring, for example, a clearer definition of what constitutes 'extreme suffering' ". We endorse the 1992 College guidelines that in the situation where the necessity for intervention 
and treatment are compelling, "on no account should the psychiatrist agree to state after treatment that the person is fit for execution". In Maryland, the sentence of a seriously ill deathrow inmate who requires treatment is commuted to life imprisonment without parole.

In the midst of the backing and filling on this topic, certain important developments are taking place. At the World Psychiatric Association (WPA) Congress held in Madrid in August 1996, the General Assembly unanimously passed the Declaration of Madrid that included the statement that "Under no circumstances should psychiatrists participate in legally authorized executions nor participate in assessment of competence to be executed".

This topic is extensively discussed in a WPA sponsored forum, entitled "Psychiatrists and Death Penalty: Some Ethical Dilemmas", in which eight psychiatrists, one lawyer and one ethicist participated, with a rebuttal by the authors of the lead article (Freedman \& Halpern, 1998).

APpelbaum. P. S. (1996) A Theory of Ethics for Forensic Psychiatry. Presidential address in Abstract of the 27th Annual Meeting of the American Academy of Psychiatry and the Law. Bloomfield. CT: APPL.

COUNCIL ON ETHICAL AND JUdiclal AfFairs (CEJA), (1995) AMA: Physician Participation in Capital Punishment: Evaluation of Prisoner Competence to be Executed: Treatment to Restore Competence to be Executed. CEJA Report 6-A-95. Chicago, IL: AMA.

Freedman, A. M. \& Halpern, A. L. (1998) A crisis in the ethical and moral behavior of psychiatrists. Current Opinion in Psychiatry, 11, 1-2.

ALFRED M. FREEDMAN, Chairman and Professor Emeritus, New York Medical College, New York, USA, and Past President, APA; and ABRAHAM L. HALPERN, Professor Emeritus, New York Medical College, New York, USA, and Past President, American Academy of Psychiatry and the Law

\section{Definition of 'haltlose'}

Sir: I was interested to read your comment on the definition of 'haltlose' (Psychiatric Bulletin. January 1998, 22, 58-59. I was also sorry to read that you had received no reply to your query from the World Health Organization (WHO).

As a former WHO staff member who was responsible for the coordination of work that led to the mental disorders chapter in ICD-10, I think I can clarify the matter for you. The term is a carry-over from ICD-8 and ICD-9. Its origin is in Karl Jaspers' description of personality variations. In Jaspers' discussion of personality types, the plural noun 'die Haltlosen' is used as a synonym for 'die Willenlosen' (the weak-willed). The English word that comes closest to the German adjective 'haltlos' in this context is 'groundless'. In fact, the relevant passage appears in the English translation of Jaspers General Psychopathology (1963) as follows:
"Those who have no will-power at all, the drifters, simply echo any influence that impinges on them ..... I think that 'drifters' in this translation is a fairly adequate rendering of 'die Haltlosen'.

The reason for retaining the term was that it used to be familiar to many European psychiatrists. With the impoverishment of psychiatric vocabulary, which unfortunately is a side-effect of the DSM-III and its successors, the connotative heritage in psychiatric terminology tends to be lost.

JASPERS, K. (1963) General Psychopathology. p. 440. Manchester: Manchester University Press.

ASSEN JABLENSKY, Department of Psychiatry, University of Western Australia, Medical Research Foundation Building, Level 3, 50 Murray Street, Perth WA6000

\section{Age can be an artificial distinction}

Sir: Close liaison between adult and children's mental health services is regarded as good clinical practice, most recently emphasised by Stormant et al (Psychiatric Bulletin. August 1997, 21, 495-497). We have recently become aware of 'children' from refugee families in inner London who are 2-3 years older than their official age. As far as we could ascertain from a computerised literature search, this has not previously been reported.

The original aim of gaining an education can ultimately block these young people's access to appropriate rehabilitative services. The 'secret' can act as a serious impediment to the professional's relationship with the adolescent and their family as well as an additional stressor in this already vulnerable group.

Older adolescents also commonly fall between adult and child psychiatry because of their age (16-17), occupation (whether or not in full-time education) or sometimes the nature of the young person's disorder is better provided for by one or other service.

Although it is tempting to apply rigid age criteria for services that are facing escalating demands, we feel that there are strong arguments not only for closer liaison between adult and child mental health services, but that the boundaries between them should be permeable. This would allow more efficient and appropriate management of these complex cases than could be provided by either service alone.

KAPIL SAYAL, Special Registrar, and Tamsin Ford, Senior Registrar, Department of Child and Adolescent Psychiatry. Bethlem and Maudsley NHS Trust, Bethlem Royal Hospital, Monks Orchard Road, Beckenham, Kent BR3 3BX 